\title{
Patient attitudes towards a new role for pharmacists: continued dispensing
}

\author{
This article was published in the following Dove Press journal: \\ Patient Preference and Adherence \\ 27 August 2014 \\ Number of times this article has been viewed
}

\section{Salem Hasn Abukres \\ Kreshnik Hoti \\ Jeffery David Hughes}

School of Pharmacy, Curtin Health and Innovation Research Institute, Curtin University, Perth, WA, Australia

Correspondence: Salem Hasn Abukres School of Pharmacy, Curtin University, GPO Box U1987, Perth,

WA 6845, Australia

Tel +6I402563627

Fax +61892662769

Email salamhasn.abukres@postgrad. curtin.edu.au
Background: In Australia, "continued dispensing" (CD) is a new model for supply of prescription medications. Under specific circumstances, community pharmacists are allowed to dispense a further one month supply of prescription only medications without a valid prescription. It allows continuation and treatment adherence when patients run out of statin and/or oral contraceptive (OC) medications, when it is not practical or they fail to plan accordingly to get a new prescription.

Objective: The aim of this study was to explore patient attitudes towards a CD model, including any perceived concerns or associated risks with $\mathrm{CD}$ prior to its introduction.

Methods: An Australia-wide computer-assisted telephone interview survey of statin and OC users aged 18 years or older was conducted in July 2013 prior to implementation of the CD model. A telephone number list was generated via a random number generation function based on a broad breakdown of the Australian population as outlined in the June 2013 Australian Bureau of Statistics data. The sample target for the survey was 300, consisting of 150 statin users and 150 OC users.

Results: There were a total of 301 respondents, comprising 151 statin users and 150 OC users. Approximately $37 \%$ of all respondents had experienced running out of their medications in the past 12 months, of whom $35.4 \%$ had temporarily stopped treatment and $33.6 \%$ requested their medication from a pharmacist without a valid prescription. OC users were more likely to run out of their medications $(P=0.021)$. The majority of respondents had a regular pharmacy $(86 \%)$ and therefore would be eligible for $\mathrm{CD}$ in the future. The majority of those surveyed had no concerns about $\mathrm{CD}$ or perceived it as posing no risks. Concerns raised included consultation privacy and the pharmacist's lack of access to their medical records.

Conclusion: Australian users of statin and OC medications showed a high level of support for CD. Given that a significant proportion of patients temporarily stopped treatment when they ran out of medications and had no valid prescription, implementation of CD may alleviate the negative consequences of therapy interruption in statin and OC users in the short term. Longerterm solutions and opportunities to expand $\mathrm{CD}$ require further exploration.

Keywords: Australia, pharmacists, statins, oral contraceptives, prescription medication

\section{Introduction}

Continued dispensing (CD) is a new supply model for certain prescription only medications in Australia when patients run out of their prescriptions. According to Medicare Australia, the CD initiative "will allow pharmacists to supply eligible PBS [Pharmaceutical Benefit Scheme] medicines to a customer when there is an immediate need for the medicine, but it is not practical for the customer to get a prescription". ${ }^{1}$ As part of the Australian government's broader National Medicines Policy, the PBS provides timely, reliable, and affordable access to necessary medicines for Australians. In regards to $\mathrm{CD}$, oral contraceptive (OC) and lipid-modifying agents, 
namely statins, are the only medication classes that can be dispensed according to current CD guidelines.

The usual practice for chronic disease prescribing in Australia is that the doctor writes a prescription for the medication for one month supply and issues up to five repeats to cover up to a 6 -month period. ${ }^{2}$ For patients meeting specific criteria, up to 11 repeats can be prescribed and therefore cover the patient for one year. ${ }^{3}$ However, there are circumstances where patients run out of their medications before the next appointment. ${ }^{4}$ As a result, they may need to ask the pharmacist to provide a supply without a prescription. ${ }^{5,6}$ The current system allows pharmacists to dispense under the provisions of Emergency Supply, Owing Prescription, or the recently introduced CD. ${ }^{7}$ The Emergency Supply system involves dispensing without a prescription and prior contact with the prescriber; however, its main drawbacks are the limited quantity of medication that may be dispensed (namely 3 days' supply), out of pocket expense to the patient, and medication wastage in the pharmacy as a result of broken packs. ${ }^{8}$ The Owing Prescription model requires prior authorization by the prescriber before dispensing and the prescriber should send the new prescription to the pharmacy within 7 days. The prescription is used to claim reimbursement for the medication from Medicare Australia through the PBS system. ${ }^{9}$ This overcomes the abovementioned disadvantages of the Emergency Supply system, but prior contact with the prescriber is not always possible or practical, and it has the potential for unpaid efforts on the part of doctors and pharmacists during the process of following up prescriptions. The CD model has been implemented to provide pharmacists with an additional option to ensure treatment continuation, and in doing so to overcome the practical drawbacks of the Emergency Supply and Owing Prescription systems. ${ }^{8}$

$\mathrm{CD}$ does not require prior authorization by the prescriber or the need to obtain a prescription, and there is no extra cost to the patient or medication wastage. In addition, the quantity dispensed under $\mathrm{CD}$ is one standard pack of the medication which is usually enough for one month, allowing adequate time for the patient to obtain an appointment with their doctor, thus avoiding potential nonadherence due to therapy interruption. ${ }^{8}$

$\mathrm{CD}$ aims to prevent patient medication nonadherence as it allows continuity of treatment when patients do not have a prescription. Patients would prefer availability of medications without prescription if they were easily accessible, reduced the need to visit their doctors and achieved at a lower cost. ${ }^{10,11}$ Therefore, easier access to medications, without a prescription or an extra cost (which CD provides) are encouraging factors to enhance patient adherence. ${ }^{12}$

On the other hand, patients' lack of awareness and acceptance, pharmacists' unwillingness to participate, and doctors' attitudes towards CD may have negative impacts on CD implementation. Pharmacists have reported low levels of patient awareness of new services provided in community pharmacies. ${ }^{13,14}$ Prior to the implementation of CD in Australia, the Australian Medical Association ${ }^{15}$ declared that it was "strongly opposed to pharmacists dispensing prescription medication without a valid prescription and without reference to the patient's treating medical practitioner".

As patient attitudes towards obtaining medication through the CD provisions have not been previously researched, this study aimed to explore their attitudes towards CD, including any perceived concerns and/or risks related to $\mathrm{CD}$ prior to its implementation in Australia.

\section{Patients and methods}

This study was approved by the human research ethics committee of Curtin University (approval number PH-06-13). Data were collected by a telemarketing company, CDM Direct Communication Services, using computer-assisted telephone interview (CATI). This method was chosen as it has the advantages of time and cost saving, and is practical when taking into the account the geographical expanse of Australia. ${ }^{16}$ It also allows respondents to ask the interviewer questions if clarification is needed. Additionally, the questionnaire usually takes less time and has been reported to be more enjoyable to answer when compared with those that are self-administered. ${ }^{17,18}$

A telephone number list was generated via a random number generation function based on a broad breakdown of the Australian population as outlined in the June 2013 Australian Bureau of Statistics data. Telephoning was carried out via random digit dialing within each state. The final target list generated had a total of 25,000 records. Telephoning was carried out by staff members of the telemarketing company who were not part of the study, therefore minimizing potential bias. This sample allowed for a prevalence estimation of $\pm 5 \%$. In addition to being either a statin user or an OC user, the respondent had to be 18 years or older and English-speaking. Respondents who used both medications were interviewed as OC users. Eligible candidates were told that the interview would take about 15 minutes and were considered consented if they answered yes to: "Would you like to participate in this interview?" If the person appeared to need assistance, then another household member was 
allowed to assist the respondent. Respondents were also offered to be called at another time if the first call timing was not convenient, and they could withdraw at any time during the interview. The study was conducted in July 2013, before the actual start of the CD supply method in Australia (September 2013). Therefore, respondents' views were not affected by any positive or negative experience with $\mathrm{CD}$, thus minimizing study bias. ${ }^{19,20}$

\section{Questionnaire design}

Data were collected using a questionnaire consisting of 38 questions. A literature review and experience from a previous study ${ }^{16}$ assisted in developing the questionnaire. It was validated by staff members within the pharmacy practice group at Curtin University and by the telemarketing company group.

The questionnaire contained three parts: part 1, which collected demographic information; part 2, which collected basic information about other disease(s) and medication, and part 3, which focused on patients' perceptions of concerns and risks associated with $\mathrm{CD}$, their thoughts on maximum number of $\mathrm{CD}$ utilizations in a 12-month period, and whether other medications should be included within the $C D$ provisions. A five-point Likert scale was used to measure respondents' attitudes towards the questions in part 3 of the questionnaire. This paper focuses on patients' perceptions of perceived risks and concerns with $\mathrm{CD}$, and the relationship between the two.

\section{Data analysis}

Answers through the option "Other please specify" were translated verbatim and thematically analyzed. The statistical analysis for closed-ended questions was undertaken in three steps using Statistical Package for the Social Sciences version 22 software (IBM Corp., Armonk, NY, USA). Step 1 was a descriptive analysis and was carried out to describe the distribution of the answers. Step 2 included assessment of respondents' overall support of CD. The study participants were not asked directly if they supported CD; instead they were asked two questions, namely, if they perceived CD as a source of any concerns and risks. For the purpose of analysis, the respondents were divided into three groups: those who perceived $\mathrm{CD}$ as a source of either concerns or risks (group $\mathrm{A}$ ), those who perceived $\mathrm{CD}$ as a source of both concerns and risks (group B), and those who did not perceive $\mathrm{CD}$ as a source of either concerns or risk (group C, ie, fully supportive). Step 3 aimed to determine if there were any statistically significant associations between concern and risk perceptions. In contrast with the null hypothesis, the alternative hypothesis assumed that participants' perceptions of concerns were affected by their perception of risks. Therefore, the binary logistic regression test was used to predict the association between perceptions of concern and risk. A $P$-value $<0.05$ was considered to be statistically significant.

\section{Results}

\section{Demographic data}

A total of 10,479 calls were made, from which there were 3,460 successful connections; of these, there were 716 outright refusals to participate, with a further 297 calls truncated early as the respondents were deemed incapable of completing the survey. Of the remaining 2,447 respondents, 2,146 were deemed ineligible, leaving a sample of 301 comprising 151 statin users and 150 OC users.

The respondents were predominantly female $(80 \%$; $\mathrm{n}=241)$. Just over half of respondents $(51.5 \% ; \mathrm{n}=155)$ were 60 years of age or younger. Almost half of the respondents (50.5\%) were from the state of New South Wales (Figure 1), and the majority lived in metropolitan areas $(84 \% ; n=256)$.

\section{Disease and medication data}

Atorvastatin (eg, Lipitor ${ }^{\circledR}$ ) was the most commonly used statin $(37.7 \% ; n=57)$ followed by rosuvastatin $\left(\right.$ Crestor $\left.^{\mathbb{R}}\right)$; $26.5 \% ; n=40)$, then simvastatin (eg, Zocor $\left.{ }^{\circledR}\right) ; 15.8 \%$; $=24$ ). Ethinylestradiol $30 \mu \mathrm{g}+$ levonorgestrel $150 \mu \mathrm{g}$ (Levlen ${ }^{\circledR}$ or Monofeme ${ }^{\circledR}$ ) was the most frequently used contraceptive agent (38.6\%; n=58) followed by ethinylestradiol 30/40/30 $\mu \mathrm{g}+$ levonorgestrel 50/75/125 $\mu \mathrm{g}$ (Trifeme ${ }^{\circledR}$, Triphasil ${ }^{\circledR}$, or Triquilar $\left.^{\circledR}\right)$ which was used by $12.6 \%(n=19)$ of OC users. Of the respondents, over a third reported having at least one other disease $(38.5 \% ; \mathrm{n}=116$, see Table 1$)$.

\section{Medication supply history}

One hundred and ten (36.5\%) of the respondents had run out of either their statin or OC in the previous 12 months (Table 1), of whom $35.4 \%$ reported that they temporarily stopped the medication until they could see their doctor, while $33.6 \%$ sought an extra supply from their pharmacists until they could see their doctor.

\section{Regular pharmacy}

The majority of the respondents $(86 \% ; n=259)$ reported having a regular pharmacy (Table 1). However, this differed amongst OC users and statin users $(74.9 \%$ versus $97.4 \%$, respectively; $P<0.0001$ ). 


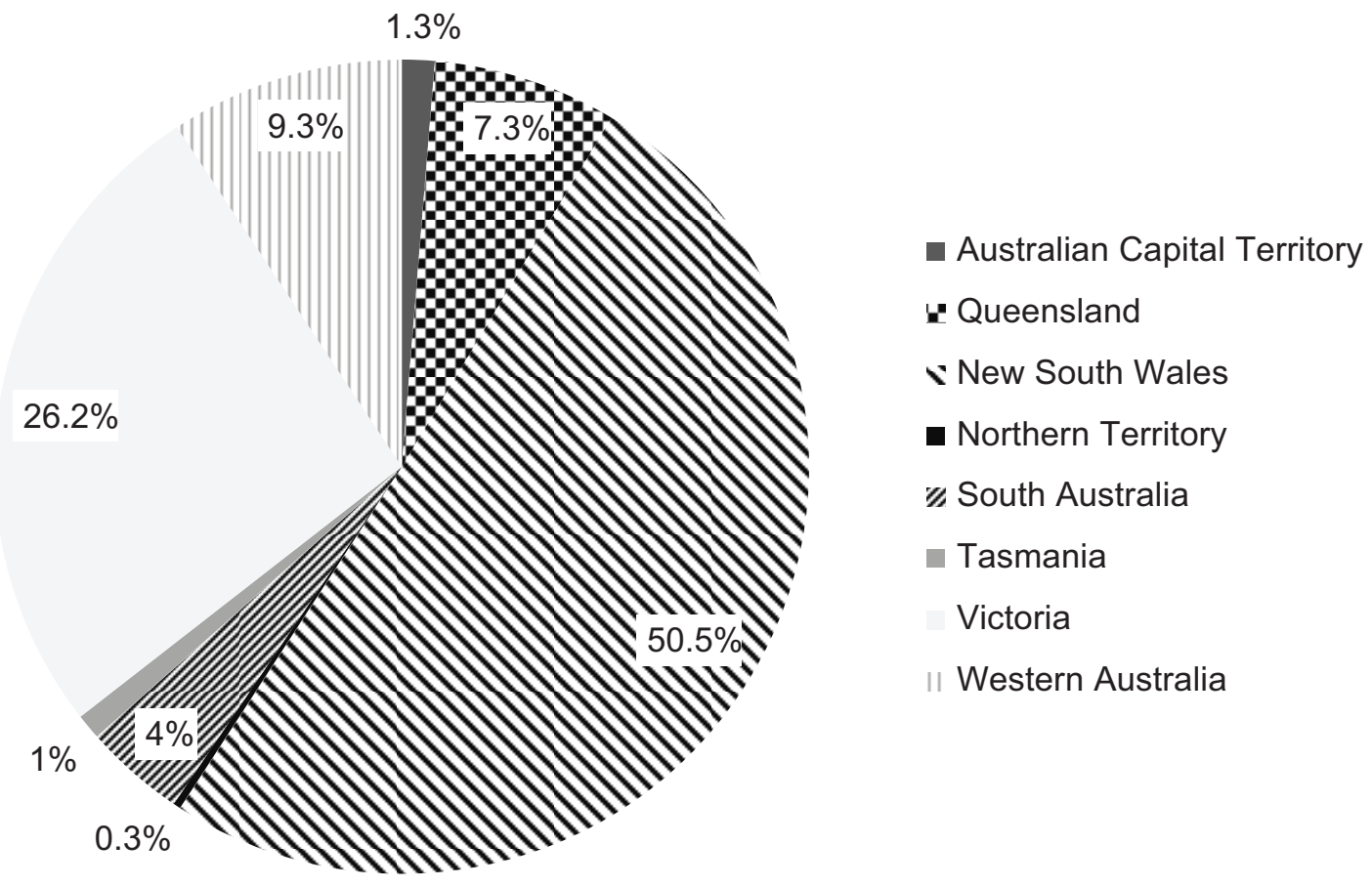

Figure I Distribution of respondents by their state or territory of residence in Australia.

\section{Perceived concerns and risks related to $C D$}

The questionnaire was designed to explore patients' concerns about $\mathrm{CD}$ and whether they thought it would be safe to obtain their medication through CD. In order to simplify and explain $\mathrm{CD}$ to the participants, $\mathrm{CD}$ was presented in the questionnaires as obtaining one additional supply from the pharmacist when the patient ran out of medication and it was not practical to see the doctor.
When patients obtain medication through $\mathrm{CD}$, they need to discuss their health issues with the pharmacist, and answer a range of questions in order for the pharmacist to determine whether $\mathrm{CD}$ is appropriate and safe. The majority of the respondents were not concerned with the planned CD initiative (89.4\%; $n=269$ ), mainly because they trusted their pharmacist's judgment in determining if it would be appropriate for them $(72.8 \% ; \mathrm{n}=219)$. Other reasons given in support of $\mathrm{CD}$ were "the pharmacist will refer me to the

Table I Respondents' characteristics

\begin{tabular}{|c|c|c|c|}
\hline Characteristic & Responses & Number & Percentage \\
\hline \multirow[t]{3}{*}{ Had other medical conditions } & No & 60.8 & 183 \\
\hline & Yes & 38.5 & 116 \\
\hline & Prefer not to disclose & 0.7 & 2.0 \\
\hline Approximate number of occasions in past 12 months when & 0 & 188 & 62.5 \\
\hline \multirow[t]{4}{*}{ respondents reported running out of their medication } & I & 52 & 17.3 \\
\hline & 2 & 33 & 11.0 \\
\hline & $>2$ & 25 & 8.3 \\
\hline & Prefer not to disclose & 3 & 1.0 \\
\hline If impractical to see usual doctor, action taken by & Nil, stop treatment & 40 & 35.4 \\
\hline \multirow[t]{6}{*}{ respondents to acquire further medication supply } & Ask pharmacist & 37 & 33.6 \\
\hline & See after hours doctor & 8 & 7.1 \\
\hline & See another doctor & 17 & 15.0 \\
\hline & Borrow & 4 & 3.5 \\
\hline & Other & 5 & 4.4 \\
\hline & Prefer not to disclose & I & 0.9 \\
\hline \multirow[t]{2}{*}{ Regular customer of a pharmacy } & No & 42 & 14.0 \\
\hline & Yes & 259 & 86.0 \\
\hline
\end{tabular}


Table 2 Respondents' perceptions of concern and risk

\begin{tabular}{llll}
\hline Question & Response & Number & Percentage \\
\hline Do you have any concerns regards CD? & No & 269 & 89.4 \\
& Yes & 30 & 10.0 \\
& Prefer not to disclose & 2 & 0.7 \\
Reasons for lack of concern & Pharmacists know if it is safe or not to take an & 219 & 72.8 \\
& additional supply when I run out of my medication & 177 & 58.8 \\
& The pharmacist will refer me to the doctor if needed & $17 \mid$ & 57 \\
& Pharmacists are easier to access than doctors & $14 \mid$ & 47.2 \\
& Reduce work load of my doctor & 167 & 55.5 \\
& It saves my time & 160 & 53.2 \\
Reasons for concern & It makes me not miss any dose of my medicine & 147 & 48.8 \\
& All of the above & 19 & 6.3 \\
& Other & 4 & 1.3 \\
& Prefer not to disclose & 6 & 20 \\
Lack of privacy in the pharmacy & 10 & 33.3 \\
Do you believe CD poses any risk? & Pharmacist has no access to my health records & 6 & 20 \\
& All of the above & 8 & 26.7 \\
\hline
\end{tabular}

Abbreviation: $C D$, continued dispensing.

doctor if needed", "pharmacists are easier to access than doctors", "it will save my time", and "it allows me not to miss any doses of my medicine" (Table 2).

\section{Respondents' perception of concerns and risk}

Amongst the 30 respondents who expressed concerns regarding $\mathrm{CD}$, the main issues raised related to consultation privacy and pharmacists' lack of access to their medical records. Some respondents stated they would prefer to see their doctor $(n=4)$, lacked confidence in the pharmacist's capabilities or training ( $\mathrm{n}=4)$, or saw $\mathrm{CD}$ as a way patients might abuse medications $(n=1)$. The majority of respondents $(88.7 \% ; n=267)$ did not see any risk associated with the $\mathrm{CD}$ process.

\section{Estimation of $C D$ support}

As outlined in the Methods section, support for $\mathrm{CD}$ was assessed on the basis of the combined responses of respondents to Q16 (Perceived concerns in discussing health issues with the pharmacist as part of CD) and Q20 (Perceived risks from pharmacists providing an additional supply of medication without a valid prescription). Respondents were deemed to be fully supportive of $\mathrm{CD}$ if they disagreed about any concerns or risks associated with $\mathrm{CD}$ (Figure 2). Two hundred and forty-nine respondents $(82.7 \%)$ disagreed with both questions (ie, those in group $\mathrm{C}$, no concerns and no risk) whilst eight (2.6\%) agreed with both questions (ie, those in group B, both concern and risk). These results indicated a high level of support for $\mathrm{CD}$ by potential users.

\section{Relationship between perceptions of concerns and risks}

Binary logistic regression analysis was used to examine if participants' perceptions of concerns were affected by their perception of risks. The null hypothesis assumed no such

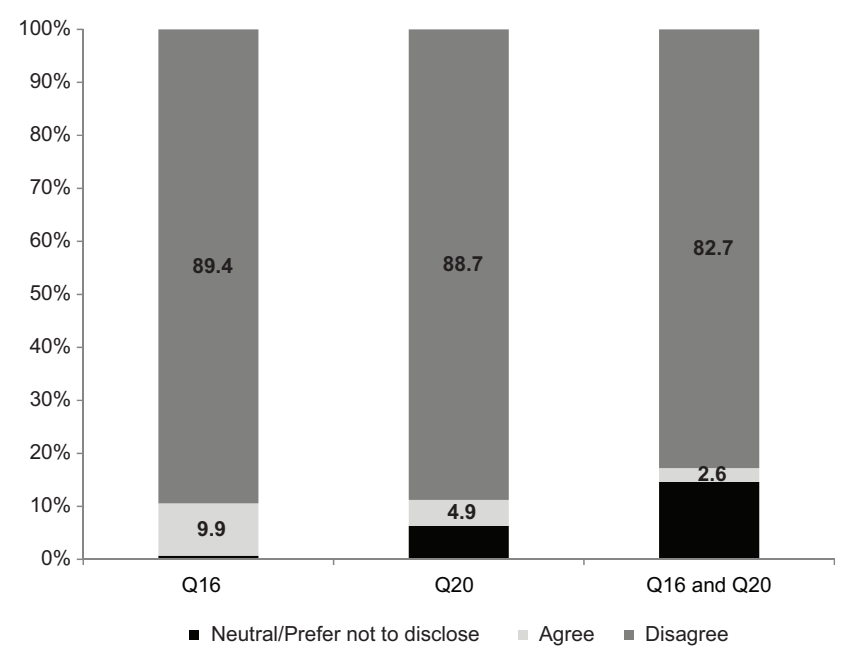

Figure 2 Proportion of respondents $(n=301)$ who fully supported continued dispensing (ie, disagreed with both Q16 and Q20).

Notes: Q16, Perceived concerns to discuss health issues with the pharmacist when providing an additional supply; and Q20, Perceived risks for pharmacists providing an additional supply of medication without a valid prescription.

Abbreviation: $\mathrm{Q}$, question. 
relationship. This analysis revealed a highly statistically significant association between respondents' perceptions of concerns (independent variable) and perceptions of risks (dependent variable; $P<0.0001$ ). "Disagreed" was the reference group. The odds ratio was 16.7 , meaning that concerned respondents were 16.7 times more likely than unconcerned respondents to agree that there would be risk associated with $\mathrm{CD}$. This suggests that participants who were concerned may be so because they thought CD is potentially risky.

\section{Discussion}

This study explored attitudes of statin users and OC users towards CD. It was conducted almost 2 months before the actual implementation of CD in Australia in September 2013, hence the results represent respondents' attitudes before any positive or negative experiences with $\mathrm{CD}$ which may have influenced their views. ${ }^{20-22}$

In the present study, the vast majority of the respondents strongly supported $\mathrm{CD}$, and did not see it as a source of any concerns or risks. The potential explanations for this may be related to consumers' trust in pharmacists assuming additional responsibilities and/or related to the nature of $\mathrm{CD}$ itself. Pharmacy consumers' trust of pharmacists assuming new roles has been reported previously in the Australian literature. ${ }^{16}$ In the present study, almost three quarters of respondents selected "Pharmacists know if it is safe or not to take an additional supply" option. Further, they thought that their "Pharmacist would refer them to the doctor when it is needed", which is consistent with previous findings..$^{23,24}$ Additionally, CD reserves the diagnosis to doctors, with pharmacists able to continue the treatment until patients can see their doctors. In previous studies ${ }^{16,25}$ of attitudes towards expanded pharmacists' roles, the majority of respondents (patients and pharmacists) strongly supported expanding the role of pharmacists to prescribe medications for diseases that were previously diagnosed by doctors (supplementary prescribing) rather than pharmacist diagnosing and prescribing (independent pharmacist prescribing). This is in contrast with the negative attitude of doctors towards $\mathrm{CD}$ as reported by the Australian Medical Association prior to its implementation. ${ }^{15}$ The Australian Medical Association described CD as an unsafe process. Whilst recognizing that not all respondents may have been qualified to estimate any risk associated with $\mathrm{CD}$, all were chronic medication users and the majority did not see it as a risky method for obtaining their medications in the short term. This may be due to their long-term use of medication and prior experience with pharmacists positively influencing their views.

As a method of medication supply, CD was instigated to minimize patient nonadherence with their medications, particularly as a result of treatment interruption, which occurs when patients run out of medication before they are able to obtain a new prescription. Although more than half of the respondents reported never being in this situation, a significant proportion had $(\sim 37 \%)$, and of these, over a third temporarily stopped treatment until they saw their doctor. Temporary discontinuation of a medication may have negative health outcomes; ${ }^{12}$ further, it may lead to permanent treatment cessation. ${ }^{26}$ Discontinuation of statins has been reported as a source of concern to doctors and pharmacists..$^{24,27}$ Significant statin discontinuation rates have been reported, especially amongst younger patients and asymptomatic cases. ${ }^{28,29}$ In the case of OC users, Rosenberg and $\mathrm{Waugh}^{30}$ reported that $80 \%$ who stopped using their OCs either adopted another less effective method of contraception or completely discontinued, even though they were still at risk of unwanted pregnancy. In an Australian study, ${ }^{31}$ approximately $90 \%$ of pregnancies amongst women aged under 18 years were unintended and $80 \%$ amongst those aged 18-24 years. In the present study, OC users, who are younger than their statin counterparts, reported running out of their medication more often than statin users $(P=0.021)$. In the case of statins, other studies have shown older users report being more adherent than younger users. ${ }^{28,29}$

Approximately one third of respondents who experienced running out of their medications had requested an additional supply from a pharmacist. Before implementation of CD in Australia, pharmacists had only two options if they were to grant such requests, ie, Emergency Supply or Owing Prescription. Both options have their disadvantages. Issues with the first include increased out of pocket expense for patients and wastage for pharmacies from open packs. Emmerton et al reported that the additional medication cost may deter some patients from purchasing medications under Emergency Supply. ${ }^{11}$ The other method, Owing Prescription, represents an administrative burden and involves unpaid effort for both doctors and pharmacists. In order to assist patients to obtain their medications at a lower cost, a pharmacist may supply a full pack of the medication and then follow up with their doctor to obtain a new prescription..$^{88}$ This "in advance supply", ie, before a prescription is issued, is generally restricted for regular pharmacy customers only, where a dual trust exists between the pharmacist and the patient. 
Statin users were less likely to run out of medications than OC users $(P=0.021)$. There are a number of possible reasons for this significant difference. Firstly, statin users were older, being more likely to be aged 60 years or over $(P<0.0001)$. It has been reported that those who are older are likely to be more adherent to their medications. ${ }^{29} \mathrm{Sec}-$ ondly, statin users are more likely to have other diseases and use more medications $(P<0.0001)$, so may have more regular contact with their doctors. ${ }^{28}$ Thirdly, statin users were more likely to have a regular pharmacy than OC users ( $97 \%$ versus $75 \%, P<0.0001$ ), and this would lead statin users to interact more with their pharmacists and be more likely to ask them for an additional supply if they ran out between doctors' appointments. In addition, pharmacists would empathically dispense when they have the medication history of the patient, which is most likely to be available for regular customers. ${ }^{32,33}$ Finally, OC users were more likely to have full-time jobs $(P<0.0001)$ when compared with statin users, so may have more difficulty in organizing a doctor's appointment. ${ }^{34}$ Moreover, OC users have the option of considering alternative contraceptive methods if they run out of OCs. ${ }^{30}$

Among those who had run out of medication, less than a quarter reported seeing another doctor or an after hours doctor ( $\sim 15 \%$ and $\sim 7 \%$, respectively). The more common actions were to stop treatment until they saw their regular doctor or ask for an additional supply from the pharmacist $(\sim 36 \%$ and $\sim 33 \%$, respectively). This indicates that patients are not in favor of changing their doctor to another doctor. This is consistent with a study of asthmatic patients that reported patients becoming less adherent to their medications if they received care from colleagues of their doctor. ${ }^{35}$

Patient acceptance of any new service is conditioned by how they perceive it. Minimizing the risk of treatment interruption, hence nonadherence, is the ultimate goal of $\mathrm{CD}$, which enables more convenient access to medications. Since pharmacists are more accessible than doctors, ${ }^{21} \mathrm{CD}$ seems to have the capacity to gain client support. This is confirmed by the results of our study, where $57 \%$ of respondents agreed with "Pharmacies are easier to access than doctors". Additionally, there were other reasons that were reported by some respondents, including trusting the pharmacist, pharmacy keeping records of dispensing, and being a regular customer and having a personal relationship with the pharmacist. On the other hand, lack of privacy and pharmacists having no access to medical records or both were identified by the small number of respondents concerned about CD. From a pharmacy perspective, inability to check medication histories for nonregular customers has been cited as a deterrent to more positive interactions, ${ }^{33}$ whilst customers' personal experiences and perceptions, positive or negative, about pharmacists may strongly affect their attitudes towards pharmacists' current and future roles. ${ }^{21}$

The limitations of this study are acknowledged. This study was conducted via landline telephone which may limit the representation of individuals who only use mobile phones, especially younger individuals. ${ }^{36}$ In addition, some population groups were not included, ie, those who could not speak English and those aged under 18 years, acknowledging that Australia is a multicultural country ${ }^{37}$ and OCs can be prescribed to teenagers younger than 18 years. ${ }^{38}$ Finally, the plan was to obtain a stratified sample of consumers according to the population distribution in Australia, but this was not achieved. The main factors potentially contributing to this were the high number of nonconnections, consumers' preference to participate, and project budget and time constraints, which may limit the generalizability of this study.

Future work should explore the attitudes of statin users and $\mathrm{OC}$ users who have experienced $\mathrm{CD}$ to find out if their experience with $C D$ has had positive or negative effects on their perceptions of $\mathrm{CD}$. At the same time, the experiences and views of community pharmacists need to be gathered to assess whether they believe CD is an ideal solution to deal with patients who run out of their regular medications. Further areas of research may include the attitudes of patients with other chronic disease diseases regarding inclusion of their medications in the CD provisions.

\section{Conclusion}

Australian users of statin and OC medications showed a high level of support for CD. Given that a significant proportion of patients temporarily stop treatment when they run out of medications and have no valid prescription, $\mathrm{CD}$ may alleviate the negative consequences of therapy interruption in statin users and OC users in the short term. Strategies addressing the issue of supply beyond the one month allowable and the currently listed therapeutic groups of medications covered under $\mathrm{CD}$ need further exploration.

\section{Disclosure}

The authors report no conflicts of interest in this work. 


\section{References}

1. Australian Government Department of Human Services. Continued Dispensing of Medicines in Defined Circumstances. 2013. Available from: http://www.medicareaustralia.gov.au/provider/pbs/fifth-agreement/ medication-continuance.jsp. Accessed February 12, 2014.

2. Britt H, Miller G, Charles J, et al. General Practice Activity in Australia 2011-2012: BEACH, Bettering the Evaluation And Care of Health. General Practice Series 31. Sydney University Press. 2012. Available from: http://books.google.com.au/books?hl=en\&lr=\&id $=\mathrm{g} 0 \mathrm{C} 6745 \mathrm{CoAoC} \&$ oi $=$ fnd $\& \mathrm{pg}=\mathrm{PP} 1 \& \mathrm{dq}=+$ General + Practice + Act ivity+in+Australia+2011-12:+Beach,+Bettering+the+Evaluation+ and + Care + of + Health.$+\&$ ots $=$ hr-veveMMB \&sig $=y I 33$ Xg91MaRfF9CYtwO8MES960\#v=onepage $\& \mathrm{q}=$ Genera $1 \% 20$ Practice $\% 20$ Activity\%20 in\%20Australia\%202011-12\%3A\%20Beach\%2C\%20 Bettering $\% 20$ the $\% 20$ Evaluation $\% 20$ and $\% 20$ Care $\% 20$ of $\% 20$ Health.\&f=false. Accessed June 11, 2013.

3. Australian Government Department of Health Services. Writing PBS/ RPBS prescriptions for Highly Specialised Drugs (HSD) medicines in public hospitals participating in pharmaceutical reforms checklist. 2014. Available from: https://www.medicareaustralia.gov.au/provider/ business/education/files/2993-writing-pbs-rpbs-prescriptions-with-hsditems-in-public-hospitals.pdf. Accessed March 12, 2014.

4. Barber N. Extended prescribing rights - the UK Experience. Australian Prescriber. 2009;32(5):118-119.

5. Barbero-González A, Pastor-Sánchez R, del Arco-Ortiz dZJ, EyaralarRiera T, Espejo-Guerrero J. Demand for dispensing of medicines without medical prescription. Aten Primaria. 2006;37(2):78. Spanish.

6. Caamaño F, Tomé-Otero M, Takkouche B, Gestal-Otero JJ. [Influence of pharmacists' opinions on their dispensing medicines without requirement of a doctor's prescription]. Gac Sanit. 2005;19(1):9-14. Spanish.

7. Hoti K, Hughes J, Sunderland B. Medication supply to residential aged care facilities in Western Australia using a centralized medication chart to replace prescriptions. BMC Geriatr. 2012;12(1):25.

8. Bessell T, Marriott J, Emmerton L, Nissen L. Improving Australians' Access to Prescription Medicines: Development of Pharmacy Practice Models. Final Report 2005. Available from: http://www.guild.org.au/ docs/default-source/public-documents/services-and-programs/researchand-development/Third-Agreement-R-and-D/2003-017/final-report. pdf?sfvrsn=0. Accessed March 6, 2014.

9. Australian Government Department of Health Services. Online Claiming for PBS. 2013. Available from: http://www.medicareaustralia.gov. au/provider/pbs/online/\#N101D3. Accessed June 9, 2014.

10. Hughes CM, McElnay JC, Fleming GF. Benefits and risks of self medication. Drug Saf. 2001;24(14):1027-1037.

11. Emmerton L, Bessell T, Marriott J, Nissen L, Dean L. Reforming the quality use of medicines in Australian aged care facilities: a new pharmacy practice model. Int J Pharm Pract. 2007;15(4):331-337.

12. Iuga $\mathrm{AO}, \mathrm{McGuire} \mathrm{MJ}$. Adherence and health care costs. Risk Manag Healthc Policy. 2014;7:35.

13. Weiss MC, Sutton J, Adams C. Exploring innovation in pharmacy practice: a qualitative evaluation of supplementary prescribing by pharmacists. Royal Pharmaceutical Society of Great Britain London; 2006. Available from: http://www.pharmacyresearchuk.org/waterway/wpcontent/uploads/2012/11/Exploring_innovation_in_pharmacy_practice_supplementary_prescribing.pdf. Accessed September 16, 2013.

14. McMillan SS, Wheeler AJ, Sav A, et al. Community pharmacy in Australia: a health hub destination of the future. Res Social Adm Pharm. 2013;9(6):863-875.

15. Australian Medical Association. Guidelines for continued dispensing of eligible prescribed medicines by pharmacists. 2012. Available from: http://ama.com.au/node/7453. Accessed April 18, 2012.

16. Hoti K, Hughes J, Sunderland B. Pharmacy clients' attitudes to expanded pharmacist prescribing and the role of agency theory on involved stakeholders. Int J Pharm Pract. 2011;19(1):5-12.

17. Harris D, Grimshaw J, Lemon J, T Russell I, Taylor R. The use of a computer-assisted telephone interview technique in a general practice research study. Fam Pract. 1993;10(4):454-458.
18. De Vaus D. Surveys in social research. Psychology Press, 2002. Available from: http://books.google.com.au/books?hl=en \&lr=\&id=x $6 \mathrm{Vp} 5 \mathrm{~N}$ O93CAC\&oi=fnd\&pg=PP2\&dq=Surveys + in + Social + Research\&ots $=Y$ MCg378Lvr\&sig=Gz5zRSRpKmKc85hWuAjldphSWjA\#v=onepage\& $\mathrm{q}=$ Surveys\%20in\%20Social\%20Research\&f=false. Accessed June 18, 2013.

19. Abu-Omar SM, Weiss MC, Hassell K. Pharmacists and their customers: a personal or anonymous service? Int J Pharm Pract. 2000;8(2): $135-143$.

20. Anderson C, Blenkinsopp A, Armstrong M. Feedback from community pharmacy users on the contribution of community pharmacy to improving the public's health: a systematic review of the peer reviewed and non-peer reviewed literature 1990-2002. Health Expect. 2004;7(3): 191-202.

21. Eades CE, Ferguson JS, O'Carroll RE. Public health in community pharmacy: a systematic review of pharmacist and consumer views. BMC Public Health. 2011;11(1):582.

22. Cooper RJ, Anderson C, Avery T, et al. Nurse and pharmacist supplementary prescribing in the UK - a thematic review of the literature. Health Policy. 2008;85(3):277-292.

23. Armour CL, LeMay K, Saini B, et al. Using the community pharmacy to identify patients at risk of poor asthma control and factors which contribute to this poor control. J Asthma. 2011;48(9):914-922.

24. McKenney JM, Brown WV, Cohen JD, Cahill E. The National Lipid Association surveys of consumers, physicians, and pharmacists regarding an over-the-counter statin in the United States: is this a good idea? Am J Cardiol. 2004;94(9):16-21.

25. Hoti K, Sunderland B, Hughes J, Parsons R. An evaluation of Australian pharmacist's attitudes on expanding their prescribing role. Pharm World Sci. 2010;32(5):610-621.

26. Fischer K, Van Der Bom J, Prejs R, et al. Discontinuation of prophylactic therapy in severe haemophilia: incidence and effects on outcome. Haemophilia. 2001;7(6):544-550.

27. Casula M, Tragni E, Catapano AL. Adherence to lipid-lowering treatment: the patient perspective. Patient Prefer Adherence. 2012;6: 805-814.

28. Chodick G, Shalev V, Gerber Y, et al. Long-term persistence with statin treatment in a not-for-profit health maintenance organization: a population-based retrospective cohort study in Israel. Clin Ther. 2008; 30(11):2167-2179.

29. Helin-Salmivaara A, Lavikainen P, Korhonen MJ, et al. Long-term persistence with statin therapy: a nationwide register study in Finland. Clin Ther. 2008;30 Pt 2:2228-2240.

30. Rosenberg MJ, Waugh MS. Oral contraceptive discontinuation: a prospective evaluation of frequency and reasons. Am J Obstet Gynecol. 1998;179(3 Pt 1):577-582.

31. Black KI, Stephens C, Haber PS, Lintzeris N. Unplanned pregnancy and contraceptive use in women attending drug treatment services. Aust N Z J Obstet Gynaecol. 2012;52(2):146-150.

32. Crump K, Boo G, Liew FS, et al. New Zealand community pharmacists' views of their roles in meeting medicine-related needs for people with mental illness. Res Social Adm Pharm. 2011;7(2):122-133.

33. Puspitasari HP, Aslani P, Krass I. Australian community pharmacists' awareness and practice in supporting secondary prevention of cardiovascular disease. Int J Clin Pharm. 2013;35(6):1218-1228.

34. Nair KV, Belletti DA, Doyle JJ, et al. Understanding barriers to medication adherence in the hypertensive population by evaluating responses to a telephone survey. Patient Prefer Adherence. 2011;5: 195-206.

35. Bender BG. Overcoming barriers to nonadherence in asthma treatment. J Allergy Clin Immunol. 2002;109(6):S554-S559.

36. Australian Communications and Media Authority. Report 2 Converging communications channels: Preferences and behaviours of Australian communications users. Communications report 2010-2011 Series 2011. Available from: http://webcache.googleusercontent.com/search?q=cache:A6E-U7hUcRAJ:www.acma. gov.au/webwr/_assets/main/lib410148/report2-convergent_comms.

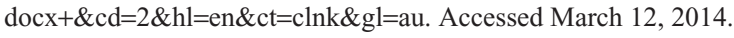


37. Dahm M. Coming to terms with medical terms: exploring insights from native and non-native English speakers in patient-physician communication. Hermes. 2012;49:79-98.
38. Hussainy SY, Stewart K, Chapman CB, et al. Provision of the emergency contraceptive pill without prescription: attitudes and practices of pharmacists in Australia. Contraception. 2011;83(2):159-166.

\section{Publish your work in this journal}

Patient Preference and Adherence is an international, peer-reviewed, open access journal that focuses on the growing importance of patient preference and adherence throughout the therapeutic continuum. Patient satisfaction, acceptability, quality of life, compliance, persistence and their role in developing new therapeutic modalities and compounds to optimize clinical outcomes for existing disease states are major areas of interest for the journal. This journal has been accepted for indexing on PubMed Central. The manuscript management system is completely online and includes a very quick and fair peer-review system, which is all easy to use. Visit http://www. dovepress.com/testimonials.php to read real quotes from published authors.

\footnotetext{
Submit your manuscript here: http://www.dovepress.com/patient-preference-and-adherence-journal
} 